\title{
IGNACIO ZULOAGA, REPRESENTANTE DE LA GENERACIÓN DEL 98 Y SU RECEPCIÓN EN EL MEDIO AMBIENTE CHECO EN LOS PRIMEROS AÑOS DEL SIGLO XX
}

\author{
POR \\ PAVEL ŠTĚPÁNEK \\ Universita Palackého, Olomous, Rep. Checa
}

Se estudia la recepción favorable de la figura de Zuloaga en el ambiente artístico de Praga, a raíz de las críticas favorables de la prensa artística checa en París, que prepararon el terreno para una Exposición en la capital checa, Praga. Asimismo el impacto que produjo sobre el pintor Karel Myslbek y en otros de su misma generación.

Palabras clave: Zuloaga, Myslbek, Paris, Praga, Pintura.

The favorable reaction to the works of Zuloaga in Paris on the part of the Czech artistic press in the French capital, paved the way for a Zuloaga exhibition in Prague. The paintings of the Spaniard produced a great impact on Karel Myslbek and other Czech artists of his generation.

Key words: Zuloaga - Myslbek - Paris - Prague - paintings.

1. «Olas» de interés por el arte español durante los últimos cien años

Hacia 1900, en la época del nacimiento del arte moderno checo, comienza la primera de varias olas de interés por el arte español en el Reino de Bohemia que se convertiría dos decenios después en un país independiente, en la República Checoslovaca. Dichas olas continúan sucediéndose casi hasta hoy día. Si las trazamos brevemente, entonces debemos comenzar por las exposiciones de la Unidad de Bellas Artes de Praga que culmina precisamente en una monográfica extraordinaria de Ignacio Zuloaga en 1904-5. Sin embargo, se adelantó en unos años el pintor Karel Myslbek, hijo del famosísimo escultor, confirmando su interés por Zuloaga con un viaje a España.

Esta primera ola está muy relacionada con la segunda, provocada por la obra de El Greco, la que inspiró en muchos aspectos la obra temprana expresionista y la cubista de los pintores checos introductores de las modernas corrientes estilísticas en el País Checo - como fueron Bohumil Kubišta, Emil Filla, Antonín Procházka, Josef Čapek y otros jóvenes, quienes entonces entraban en la escena artística. Tampoco puede omitirse - en la misma época- el interés 
por Goya quien maravilló sobre todo al pintor y crítico Miloš Jiránek (1875-1911) '. Los primeros contactos con su obra ocurrieron, naturalmente, de manera indirecta, a través de París, menos Alemania y excepcionalmente la capital del Imperio Austro Húngaro del cual dependía el Reino de Bohemia, Viena. A pesar de que ya antes de la pimera guerra mundial varios pintores y críticos de arte han emprendido un viaje a España (Kramář, Čapek, etc.), las influencias e inspiraciones españolas que se suceden una tras otra, en un flujo inmediato, casi coetáneas, llegan en su mayoría a través de París y de otros centros europeos ${ }^{2}$.

La tercera ola la forma el interés por la obra de Picasso y el estilo por él impuesto, el cubismo (especialmente Gris), como le representa la actividadad del grupo Osma (El Ocho) y del teórico Vincenc Kramáŕ quien fue de los primeros en haber entendido el nuevo estilo, convirtiéndose en su difusor muy identificado.

La cuarta, no menos clara e independiente, la podemos ver en la influencia de la obra de los grandes surrealistas españoles (Dalí, Miró, González), cuyas personalidades se imponen dentro del marco del surrealismo internacional, y se reflejan en la obra de los jóvenes surrealistas checos como Tikal, Janoušek, Muzika y otros. En este período podríamos incluir asimismo, más bien por motivos cronológicos y no estilísticos, también el conocimiento directo, hasta, podemos decir, el turismo artístico, de artistas checos de la mayor diversidad de estilos, quienes comienzan a viajar en los años veinte y treinta a España, como lo notamos en casos de Rambousek, Rykr, Š́ma y Kars (aunque este último emprendió su primer viaje antes de la Primera Guerra).

Casi inmediatamente sucede la quinta ola, provocada por la Guerra Civil Española, y cuyos primeros síntomas supo captar perfecta y sensiblemente un artista tan apolítico como Josef Š́ma; en esta ola confluyen varias de las indicadas más arriba.

Dicha quinta ola pasó orgánicamente, al pasar la segunda guerra mundial, en la sexta etapa, en la de la exposición de los españoles de París, o los españoles republicanos, como ellos mismos se titularon, que tuvo una enorme importancia para el país y que despertó un enorme eco. Han tomado lección de ella o han simpatizado con ella muchos artistas checos y eslovacos jóvenes o maduros, en los que aún más tarde observamos ecos inspirativos dalianos (por ejemplo, el joven Mikuláš Medek o el surrealista ya hecho Josef Istler).

Posiblemente la última ola, la séptima, quizás menos identificable en detalles, y más suave en su influencia, ocurrió en los años sesenta, cuando el país buscaba una salida del llamado realismo socialista ortodoxo que sin éxito pero con insistencia imponía el regimen comunista, dejando huellas notables, tanto en haber renovado el interés por las vanguardias históricas, después de un ayuno politico histórico de unos veinte años (en los cincuenta), y por otra, interesándose por la pintura abstracta de un Antoni Tapies y su círculo, estimulada en los últimos años de la llamada «normalización»o sea, vuelta a los años dogmáticos del comunismo, que escapaban, gracias a las exposiciones españolas de arte abstracto - debido a que el estado comunista tenía que ceder en algunos detalles al deseo del país con el que se entablaron relaciones diplomáticas en una época muy reciente- al esfuerzo por normalizar. Posiblemente, la parte final represente una ola más, la octava, contemporánea.

\footnotetext{
1 Pavel Štěpánek, «La recepción crítica de Goya en Praga a comienzos del siglo Xx», en: Congreso Internacional «Goya 250 años después. 1746-1996». Museo del Grabado español Contemporáneo, Marbella. 10-13 de abril de 1996. Actas, Madrid 1996, p. 317-326.

${ }^{2}$ A la misma ola del interés por España podemos incluir entre otros, las enseñas pintadas por artistas checos como Luděk Marold, copiadas luego por Miloš Jiránek (ambos en la Galería Nacional de Praga). Véase Copia de la enseña Luděk Marold (O 8595) de hacia 1893 - Español, enseña para estanco, óleo sobre madera. $92,5 \times 27 \mathrm{~cm}$. O 12394 . Al dorso, estampilla «L. Jiránek, Pekárna českých sušenek (Panadería de galletas checas), Hloubětín, Mezivrší». El cuadro parejo es Española, O 12395 .
}

$A E A$, LXXVI, 2003, 301, pp. 39 a 53 


\section{Cambio de criterios acerca de la pintura del siglo XIX}

La pintura del siglo xIx sufrió, casi por todas partes menos la ex URSS, un largo rechazo desde los mismos momentos del nacimiento de las vanguardias históricas que hoy, en la época que se asoma al postmodernismo, también son, en parte, un pasado. Después de un rechazo categórico y casi total de los pintores de salón y académicos, durante un largo tiempo considerados en algunos manuales básicos de la pintura española - aún a finales de los años cincuenta por lo menos como secundarios ${ }^{3-}$, produjo un cambio en la apreciación de su obra y - de manera similar como en este país- la consecuencia fue una nueva valoración.

El denominador común de esos despreciados y hoy nuevamente apreciados artistas, es que en gran parte pasaron una larga temporada, si no toda la vida, en París y Roma, adhiriéndose allí sobre todo a las tendencias conservadoras. Hay que adelantar que dichos artistas nuevamente valorados no representan las corrientes vanguardistas o últimas, o artistas de mayores impulsos. Aun así, y a pesar de ello, ofrecen un panorama de ciertas tendencias de la pintura española, correspondientes a las respectivas corrientes que movían toda Europa, en su camino hacia una personal síntesis de la pintura tradicional académica con los nuevos estímulos, ante todo impresionistas y modernistas. Sin embargo, hay excepciones que confirman la regla de que se podía ser tradicional y al mismo tiempo vanguardista. Entre ellas vemos al artista que mejor representa la generación del 98, Ignacio Zuloaga.

\section{Ignacio Zuloaga (1870-1945)}

Quizá sea oportuno presentar a Zuloaga y su papel en la Generación del 98. Brevemente, el pintor Ignacio Zuloaga nació en Eibar, en 1870, y falleció en Madrid en 1945. Su vida discurrió en Madrid y Roma, donde se formó, y luego, a sus apenas veinte años, en 1889, viájó a París para conquistarla. El mismo año, cuando comienza en literatura y en pintura a desgajarse un movimiento simbolista, Zuloaga entró en contacto con el nuevo medio ambiente, sobre todo con los impresionistas como Degas, que reconocieron el mensaje de un Gauguin, por ejemplo; entre ellos están Toulouse-Lautrec, Emile Bernard, Maurice Denis y el crítico Charles Maurice $^{4}$. Y, sobre todo, hombres de la generación de Zuloaga. Sus frecuentes inquietudes viajeras le llevan también a Inglaterrra, donde admiró a Whistller, y a recorrer España, especialmente Andalucía, donde permaneció durante tres años (desde 1892), y donde frecuentó la escuela taurina de Manuel Cardona. Los temas andaluces y taurinos los expone en París en 1895. El crítico año 1898 descubre Segovia, llegando a identificarse, desde el punto de vista pictórico, con sus tipos y costumbres. Aquí da el primer paso en su evolución de un pintoresquismo más o menos moderno a una nueva forma de sentir «lo típico» como algo espiritual, como la base elemental de una mitología de lo español ${ }^{5}$. Volvió a París en 1892, y desde esa ciudad, «conseguiría un eféctivo renombre internacional, sobre todo después de superar su primera fase - la de su España «blanca»-adentrándose en una visión frecuentemente dramática de los hombres y el paisaje de Castilla. Junto con José Gutiérrez Solana (1886-1945) representa en

\footnotetext{
${ }^{3}$ Juan Antonio Gaya Nuño, Arte del siglo xIx. Ars Hispaniae, Historia universal del arte hispánico. Vol. 19, Madrid 1958. Poco antes introdujo el catálogo de una gran exposición del arte español del s. xIx, pero allí mismo declaró que la pintura histórica fue un gran error. Véase Joaquín de la Puente, Un siglo de arte español (1851-1956). Madrid 1956.

${ }^{4}$ Enrique Lafuente Ferrari, La vida y el arte de Zuloaga. Revista de Occidente. Madrid 1972, 2." ed., p. 225.

${ }^{5}$ Véase Enrique Lafuente Ferrari, Los Genios de la Pintura Española, Zuloaga. Madrid 1983, p. 75. Me atengo a las fechas de la vida de Zuloaga que aparecen en este libro, pues suelen oscilar.
}

AEA, LXXVI, 2003, 301, pp. 39 a 53 
su pintura el espíritu de la literaria generación del 98» ${ }^{6}$. Dicho en otras palabras, con él, «la generación del 98 se hace pintura» ${ }^{7}$. Hoy, la crítica opina que «frecuentemente se le ha acusado de retratar una España a extinguir, excesivamente cargada de tintes sombríos, pero lo cierto es que se trata de un gran pintor...» ${ }^{8}$. En París comenzó a interesarse, junto con Santiago Rusiñol y otros jóvenes modernistas catalanes (Casas, Jordá), por la obra de El Greco (aunque ya había estudiado en sus años mozos en el Prado, copiando un retrato de caballero del pintor griego) ${ }^{9}$, y con él participa en la famosa fiesta de instalación del museo Cau-Ferrat de Sitges ${ }^{10}$.

Hacia el mismo año 1898 madurará el lenguaje plástico de Zuloaga que obtiene merecidos éxitos internacionales ${ }^{11}$. Quizá sea porque se dedicó a caracterizar tipos españoles, especialmente mujeres ataviadas con ampulosos trajes de volantes, mantones, mantillas, abanicos y flores, (que se ha venido a denominar como la época de la España blanca). «Su creación deriva de la gran tradición realista de Courbet, a la que se han sumado los recursos técnicos del impresionismo y del postimpresionismo; pero todo teñido desde la lectura trágica y regeneracionista de «problema de España», consolidando, así, hacia 1905, este otro estilo que ha dado en llamarse de la «España negra». La producción de Zuloaga se mantiene entre estos dos polos, y su habilidad para introducirse en los ambientes cosmopolitas lo convertirá en uno de los pintores españoles más reconocidos internacionalmente, un artista poderoso que participó, por ejemplo, en la selección de obras para la exposición de Venecia de 1905 y que le lleva a retratar las grandes figuras de la aristocracia y la burguesía en Europa y las dos Améri$\operatorname{cas}^{12}$. Zuloaga fue, en breve, típico representante de la Generación del 98, la que se propuso renovar España, que más tarde elevaría la fama de la España derrotada entonces por los Estados Unidos en la Guerra por Filipinas y Cuba ${ }^{13}$, «la generación dolorosa que ha creado la actual gran España cultural» ${ }^{14}$, al decir de Václav Černý.

La movida literatura que se cernió sobre los temas y la tradición que Zuloaga trataba, «la tan debatida "cuestión Zuloaga», que hizo de su obra un pretexto para la discusión de los tópicos del 98 (patriotismo y antipatriotismo, España y Europa, inmovilidad y progreso, etcétera)» ${ }^{15}$. Brevemente, pinta «la España esencial, paisajes de la meseta (castellana), de Aragón, Navarra o La Rioja; por eso se le ha podido considerar como el pintor representativo del espíritu inspirador de los artistas y escritores de la generaciion del 98». Pinta «... lo potente, lo recio, lo áspero y hasta lo agrio...».

Sentía, como Unamuno, el paisaje cuando cantaba en sus famosos versos : «Tú me levan-

6 Joaquín de la Puente, Museo del Prado. Casón del Buen Retiro, pintura del siglo xIX. Madrid 1985, pp. $254-255$.

${ }^{7}$ Emiliano M. Aguilera. «Zuloaga y la "Generación del 98"». Historia y vida, (Barcelona) III, Nov. 1970, c. 32, pp. 56-71.

8 Museo Español de Arte Contemporáneo. Catálogo. Tomo II. Madrid 1983. pp. 307-309.

${ }^{9}$ Lafuente, op. cit., nota 5, p. 74.

${ }^{10}$ Allí instalan a San Pedro y la Magdalcna. Véase también Francesc Fontbona i Francesc Miralles, Del modernisme al Noucentisme, 1888-1917. Barcelona 1985, p. 27.

1 Carlos Reyero y Mireia Freixa, Pintura y escultura en España. 1800-1910. Madrid 1995, p. 300 le incluye en el capítulo de la recepción de la modernidad. Este libro da distintas fechas de sus estancias en París que los anteriores.

${ }^{12}$ C. Reyero y M. Freixa, op sit., nota 6, p. 300. Más tarde, retrata a sus amigos como Unamuno, Pérez de Ayala, Valle-Inclán, Falla, Azorín, etc., pero asimismo al rey Alfonso XIII, cuyo gobierno de 1902 a 1931 coincide con el mayor apogeo del reconocimiento de Zuloaga en España.

13 Véase The Art and the Era of the Spanish Generation of '98. Tiempo y Arte del 98 español. Banco de Bilbao, London 1980, cat. ed. Joaquín de la Puente, Enrique Lafuente Ferrari; otros textos Julián Marías, Guillermo Díaz Plaja. Fueron representados, aparte de Zuloaga también Darío de Regoyos, Ricardo Baroja, Daniel Vázquez Díaz y José Gutiérrez Solana. Una característica detallada de la importancia de la generación del año 1898 véase por ejemplo en Juan Chabás, Déjiny španélské literatury (Historia de la literatura española). Praha 1960, p. 295.

14 Václav Černý, «Cervantes a jeho Don Quijote» (Cervantes y su Don Quijote), in: Tvorba a osobnost (Obra y personalidad), Praha 1993, p. 29 (escrito en 1931).

${ }^{15}$ Lafuente, op. cit., nota 5. p. 76.

AEA, LXXVI, 2003, 301, pp. 39 a 53 
tas, tierra de Castilla, / en la desnuda palma de tu mano...» ${ }^{16}$. Sus vistas son épicas, insistentes, críticas y pesimistas en algún aspecto, de acuerdo al criterio de su generación, partiendo de la infrahistoria española, inspirándose en algunos rasgos barrocos; sus perfectas composiciones con figuras casi escultóricas las domina el ritmo sinuoso, propio del modernismo.

Así, en 1898 es ya pintor consolidado, alcanza una primera medalla con Víspera de la corrida en la exposición de Barcelona y mantendrá dos talleres abiertos, en París y Segovia que alterna en largas temporadas. Es, sin duda, pintor novecentista, ampliamente representado en el respectivo departamento del Museo del Prado, en el Casón del Buen Retiro, y hoy, en el Centro de Arte Reina Sofia, aunque con su expresionismo y la mayor parte de su vida pertenece más al siglo xx, si bien por su carga literaria y su forma está ligado más al siglo pasado.

Participó en muchas exposiciones internacionales, pero su primera gran individual se efectuó en el país enemigo, en Nueva York en 1909, unos diez años después de la trágica guerra del 98 y las hostilidades entre los dos países, y Zuloaga atrajo 75.000 personas que acudieron para ver su exposición en la Hispanic Society ${ }^{17}$. A continuación, su obra fue causa de admiración en muchas ciudades norte y sudamericanas, como Pittsburgh, Boston, Buffalo, Cleveland, San Luis y Minneapolis, así como México, La Habana, Chile y Buenos Aires. Sin embargo, aparte de materializar plásticamente las ideas regeneracionistas, sus relaciones con la generación del 98 son archiconocidas y documentadas ${ }^{18}$. Puede decirse que Zuolaga es el retratista del 98 y por afinidad intelectual uno de los miembros de la misma generación. Fue amigo de muchos pintores, escritores, intelectuales y músicos españoles, entre ellos Valle Inclán, Pérez de Ayala, Marañón, Unamuno, Azorín, Maeztu, uno de los más tempranos panegiristas del pintor, Falla y Albéniz (testigo de su boda), a quienes les hizo aún más famosos con sus retratos. En todos ellos, Zuloaga buscaba aunar los rasgos humanos con los elementos simbólicos, con un estilo de gran caracterización. También mantenía relaciones amistosas con intelectuales residentes en París, entre otros, con Maurice Barres, autor del libro sobre El Greco ${ }^{19}$, Proust, Gide, Blume, Strindberg, Anatole France, Gabriele d'Anunzio, la Condesa de Noilles y Sarah Bernhardt ${ }^{20}$. No menos importante es su amistad con el escultor francés Rodin y su secretario el poeta Reiner Maria Rilke, de la cual hablaremos más adelante.

4. Españoles en las exposiciones de la Unidad de Bellas Artes de Praga (Krasoumná jednota) entre los años 1891 - 1910

Al lector español habrá que recordarle que dicha Unidad de Bellas Artes de Praga (en original, Krasoumná jednota, conocida también en alemán como Kunstverein für Böhmen) fue una

\footnotetext{
${ }^{16}$ Lafuente, op. cit., nota 5. p. 9.

17 Más tarde, vuelve a Estados Unidos con una gran exposición que recorrió las principales ciudades de Estados Unidos, así como en 1924, cuando le recibió el presidente de los EEUUl Coolidge. Las exposiciones en Estados Unidos fueron reconstruidas por The Spanish Institute of New York, bajo el título de Ignacio Zuloaga in America, 1909-1925, February 2 - April 29, 1989. También alcanzó un éxito apoteósico en La Habana.

18 J. Ignacio Tellechea Idígoras. Zuloaga y Unamuno. Glosas y unas cartas inéditas. Madrid 1987.

${ }_{19}$ Maurice Barrés, Greco ou le secret de Tolede. París 1923. Nouvelle édition augmentée de quelques pages inédites avec seize reproductions hors texte. La referencia a este libro en checo véase V. Ertl, «El Greco čili tajemství Toleda (El Greco o el secreto de Toledo)». Volné směry. 1910, p. 174.

20 Véase Jesús María de Arozamena, Ignacio Zuloaga, el pintor, el hombre. San Sebastián 1970, p. 142. Y de aquí hay posibles relaciones directas a Alfons Mucha quien la había hecho famosa con sus carteles. La serie de retratos la inició hacia 1917 con el inacabado de Ortega y Gasset, con fondo de el Escorial, luego Gregorio Marañón (1919), Unamuno, etc. A propósito de Ortega, éste comienza a descubrir Castilla y los colores nacionales a través de varios de los cuadros del vasco, al decir de E. M. Aguilera, op. cit., nota 7. J. Ortega y Gasset, Notas. Madrid 1959, VII ${ }^{\text {a }}$ edición, pp. 49-61, es autor de uno de los análisis más profundos del cuadro Enano Gregorio el Botero, escrito que surgió como reacción al triunfo de Zuloaga en la exposición de Roma y a raíz de haberle dedicado la revista Kunst fuer alle un número a este pintor.
} 
variante de las asociaciones de apoyo al arte ${ }^{21}$. Surgió en 1835, siendo reorganizada en 1839, fue activa como sociedad anónima. Con el tiempo se fusionó con Unidad de Amigos Patrióticos del Arte, asociación aristocrática surgida ya en 1796, que apoyaba la creación de la Academia de Bellas Artes y la Pinacoteca que más tarde se convertiría en la actual Galería Nacional de Praga.

Para facilitar la vida a los artistas y para contribuir a una mayor difusión de sus obras, las compraba y subastaba. Además, se ocupaba de las exposiciones anuales de los alumnos de la Academia de Artes Plásticas, costumbre que se mantuvo hasta hoy, así como publicaba Premios que consistían en grabados y costeaba algunos trabajos monumentales.

Sin embargo, su trabajo más importante consistía en organizar los «salones» de arte que se celebraron hasta la primera guerra mundial. Desde el año 1840 se admitían también obras de artistas extranjeros, ante todo alemanes, pero no fue antes de 1870 cuando puede decirse que ya tenía carácter realmente internacional. A partir de esa fecha, empezó a organizarse una especie de Salones, exposiciones internacionales, en los cuales participaban artistas de importancia europea. Así, por ejemplo, participaron, entre otros extranjeros, pintores como Boudin, Bompiani, Matejko, y entre los checos, aquellos de mayor renombre internacional que fueron activos — naturalmente - en París: Hynais, Chitussi, Radimský.

Paralelamente, La Unidad organizó también —-dentro de las presentaciones anuales- exposiciones llamadas extraordinarias que eran simplemente muestras monográficas de diferentes pintores - o incluso presentaciones de un solo cuadro famoso- que habían llamado la atención anteriormente con algún premio. Desde 1885, las exposiciones se celebraron en la Casa de Artistas Rudolfinum, pero la importancia de las mismas comenzó a declinar, siendo eclipsada finalmente por las exposiciones de otras entidades, más al día, sobre todo la Asociación de Artistas Plásticos Mánes (SVUM) y la Tertulia Artística (Umélecká beseda). Concluyendo, dichas exposiciones de la Unidad de Bellas Arles ofrecían, hasta el año 1905, la principal oportunidad de ver muestras de arte contemporáneo de todo tipo en Praga, como lo confirma asimismo la presencia de los españoles, notable a partir del año 1891 que culmina con Zuloaga.

Hay que recordar, sin embargo, que la escena artística de la segunda mitad del siglo pasado estaba - no sólo en Francia, donde nacían nuevas corrientes, sino en toda Europa - un poco más complicada para que puedan separarse estrictamente las nuevas tendencias vanguardistas que traían novedades, de las conservadoras. Estas últimas, naturalmente, mostraban mayor coherencia y consistencia. Las fórmulas de los viejos maestros se sometían, sin embargo, a innovaciones parciales y se enriquecían con estímulos no reconocidos pero sí notables sobre todo a distancia del tiempo, que se desprendían de la reacción frente a las conquistas formales nuevas.

La crítica de arte en Praga, publicada a la sazón en periódicos en su mayoría, sobre todo en los influyentes diarios (escritos en alemán), que no sólo comentaban lo que ocurría en el país, sino que tenía corresponsales propios en distintos centros culturales, como Bohemia ${ }^{22}$ y Politik $^{23}$, quería salir al paso al lector y su punto de vista era tributario de los visitantes, con miras a efectos extraartísticos, más bien literarios, como era corriente en la época. Encontramos aquí toda una serie de testimonios del esfuerzo por entender y distinguir los auténticos valores. El mismo hecho de que los españoles no fueron pasados por alto en dichas críticas, como hoy muchas veces sucede, testimonia una pericia de miras amplias.

\footnotetext{
${ }^{21}$ Nová enyklopedie českého výtvarného umění (Nueva enciclopedia de las artes plásticas checas), A-M, I. Praha 1995, p. 401 (Kunstverein fùr Böhmen)

${ }_{22}$ Ed. Engels, Die Ausstellung der Münchener Secession. Bohemia. 24. 6. 1902, Beil. 172, p. 2, se fija en el retrato de una actriz; K. Lahn, Pariser Brief. Bohemia, 1 de mayo de 1903. Beil. 119, p. 1.

${ }^{23}$ Por ejemplo, el crítico checo F. X. Harlas, Prager Salon 1905. Politik, 31 de Mayo de 1905, n. ${ }^{\circ} 148$, p. 1 hace notar de Zuloaga dos obras: Prächtige Typen aus dem Volke. Tánzerin auf dem Podium, o sea tipos populares y una bailarina en el podio.
}

$A E A$, LXXVI, 2003, 301, pp. 39 a 53 
Los españoles se adhieren a las primeras exposiciones de la Unidad de Bellas Artes, como quedó dicho, el último decenio del siglo pasado, a partir de 1891. El primero que aparece en Praga es, aquel año, José Benlliure y Gil (1855-1937), activo a la sazón en Roma, cuyo Retrato del hijo del artista como monaguillo lo prestó el propietario, el conde-arzobispo Gran Duque von Schönborn. Es decir, su obra ya era conocida por coleccionistas locales, aunque, como en este caso, con acceso a Roma. El segundo cuadro, El Mes Mariano en Valencia lo mandó el propio artista desde Roma. (De entre los cuadros de este artista, la Galería Moderna escogió y compró más tarde un cuadro de Benlliure que hasta hoy es prodiedad de la Galería Nacional de Praga, aunque sin exponerse: el de La entrada de los toreros en la arena) ${ }^{24}$.

Al mismo tiempo, en dicha década de los noventa, se presentaron también otros artistas españoles, pintores o escultores, entre ellos Enrique Serra, José Juliana, Ricargo Villegas, Luis Jiménez, Mariano Benlliure, Aniceto Marinas García, Manuel Garcia y Rodriguez, José Gallegos (también de éste se quedó en la actual Galería Nacional un cuadro: Un día de verano ${ }^{25}$, y muchos otros cuya obra cayó en el olvido durante el último siglo pero que, en los últimos años, se está rehabilitando artísticamente. Su obra y su aporte a las exposiciones de la Unidad de Bellas Artes antes de la Primera Gran Guerra es objeto de un estudio aparte ${ }^{26}$.

\section{Zuloaga visto por los checos en París}

A1 finalizar el año 1904 y a principios del año siguiente, ocurrió lo más importante para nuestro punto de vista: en Praga se expusieron conjuntos bastante grandes de obras del entonces más famoso pintor español, Ignacio Zuloaga ${ }^{27}$. Antes, Zuloaga ya había triunfado en Dresde (1901), donde consiguió la gran medalla de oro, igualmente en Venecia y otra vez en París, en la Exposición de la Société Nationale (1903), cuando la crítica «sólo habla de él» ${ }^{28}$, con Bailarinas españolas. El mismo año de 1904, alcanzó un triunfo sonado en Düsseldorf, pues le cedieron una sala indiviudal, privilegio tan sólo otorgado a él, Rodin y a Menzel.

Y ya estamos en el tiempo de la exposición de Praga que casi coincide en fechas con el gran banquete que se da en su honor en Madrid, al que asisten todos los intelectuales y artistas del 98, que había precedido su entrada en la posición de un pintor auténticamente «nacional», aunque España tardaría mucho en reconocerlo realmente ${ }^{29}$. Este éxito continúa luego con exposiciones en Rotterdam y Amberes.

En aquella época, su obra se conocía muy bien en el ambiente checo - sobre todo gracias a algunos pintores-, pues se estaba à jour de lo que ocurría en París; en primer lugar Jan Dědina y luego Miloš Jiránek, en su reflexión teórico-crítica ensalzaron su obra, y en segundo lugar, a su vez, en la práctica pictórica, a nivel de la aceptación de algunos elementos de su pintura, a Karel Myslbek.

Zuloaga era realmente popular y durante un largo tiempo fue recibido positivamente en Praga. Parece que el primero que escribió - desde París, por supuesto- sobre Zuloaga en prensa especializada, fue el pintor Jan Dědina, colaborador de Mucha, en el artículo publica-

\footnotetext{
${ }^{24}$ Adquirido el año 1894, óleo sobre tela, $68 \times 116$, por 10.000 florines.

25 Un día de verano, adquirido en 1891?, óleo sobre madera, por 1.000 coronas.

${ }^{26}$ La participación española en las exposiciones de la Unidad de Bellas Artes, que se publicará en la revista Uméní de Praga.

${ }^{27}$ N. ${ }^{\text {os }} 201$ a 209, de ellos, ocho cuadros y un aguafuerte. Véase apéndice documental. Me resisto a hablar de la vida del artista, pues está ampliamentc documentada. Véase E. Lafuente Ferrari, op. cit., nota 5, donde hay numerosas referencias a su bio- y bibliografia.

28 Lafuente, op. cit., nota 5. s. 8.

${ }^{29}$ Lafuente, op. cit., nota 5, p. 75.
} 
do en la prestigiosa revista mensual checa de su tiempo Volné sméry (Tendencias libres) ${ }^{30}$. Dédina comienza su análisis de la obra de Zuloaga con las siguientes palabras: «... me excitan auténticamente tres retratos en un sólo lienzo de Zuloaga Ign(acio). Dos jóvenes españolas en trajes negros con alto peinado de mantilla (los encajes llegan hasta la cintura). En el cielo violeta lucen sus blandas caras redondas pálidas. A la izquierda (suya) está un hombre envuelto en un manto y un galgo. La muchacha que está en el mismo centro del cuadro es la más perfecta. La flor amarilla en el peinado y sobre el pecho izguierdo refleja tanto más las figuras del fondo airoso violeta del cielo. El cuadro es la misma realidad De los labios de coral traslucen los dientes de la sonrisa. Todo está pintado de manera ligera, con seguridad y elegancia natural y maestra. Hela aquí delante de mí, me reclama que me quite el sombrero! Su mano izquierda está apoyada en la cadera y me mira con sus ojos pardos brillantes. Su figura es viva, respirante, desde sus pestañas negras, sus senos, caderas, simple falda negra hasta la puntera del pequeño zapato de charol. A la derecha está una muchacha más peque$\tilde{n} a$, asimismo bien plantada, un poco más sometida, la del otro (lado) con cara roja y con el sombrero sobre la cabeza. Estos son dos maestros que saltaron en las alturas como dos halcones» ${ }^{31}$. Esa excitación del artista-crítico checo es comprensible, sobre todo si recordamos que el famoso crítico alemán Maier-Graefe, quién fue, entre otras cosas, uno de los mayores difusores de la obra de El Greco, exclamó ante el cuadro: «España se despierta» ${ }^{32}$.

A Dědina se suma al año siguiente otro pintor y sobresaliente crítico Miloš Jiránek quien, al comentar la Exposición de París, afirma, en la misma revista: «También España tiene hoy un sólo, único artista, un gran pintor, quien hace voto abierto por la escuela de Velázquez y Goya. En el Museo de Luxemburgo vi un cuadro sobresaliente de él; es Zuloaga. En el Gran Palacio (de París) nos hace falta, y he encontrado en una revista local (entiéndase, de París) una mención «que el jurado encontró manera como eliminarlo, como refutarlo». Oh, esos jurados!» ${ }^{33}$.

${ }^{30}$ El pintor Jan Dědina, «Pařížský salon roku 1899». Volně směry, III, 1899, pp. 398-399. Según la descripción de Dědina puede identificarse fácilmente el cuadro: se trata del lienzo Mi tío y mis primas, del año 1898, hoy en el Musée d'Orsay, París. Véase E. Lafuente Ferrari, op. cit. nota 5. n. ${ }^{\circ}$ 10, p. 75 y 85. Fue pintado en Segovia y expuesto en el Salón de la Societé Nationale de París, en 1899, con un éxito rotundo. Dědina, a su vez, colaboró con Mucha, Besnard y Munkácsy.

31 J. Dědina, ibid.; el segundo maestro mencionado es el francés Gaston La Touche, cuya obra fue comentada con anterioridad a Zuloaga.

${ }^{32}$ Lafuente, op. cit., nota 5, p. 8. Véase la traducción al checo Julius Meier-Graefe: Grecủv barok (El barroco de El Greco). Volné smèry XVI, 1911, c. 2-3, p. 74.

${ }^{33}$ A propósito, Lafuente, op. cit. nota 5 p. 75 dice que Zuloaga decidió enviar a la Exposición Internacional de París el cuadro que le había valido la primera medalla de la Exposición de Barcelona 1898 , Víspera de la Corrida, que era asimismo su primer gran cuadro de composición. Sin embargo, con sorpresa de todo el mundo, el Jurado oficial de la selección española lo rechaza alegando oscuros pretextos... pero más tarde, envió el cuadro a la VII Exposición de Bruselas, donde lo compra el Estado belga. «A partir de entonces, Zuloaga conquista Europa». Miloš Jiránek. Listy z Paříže. 11. Volné směry $\mathrm{V}, 1900,{ }^{\circ}{ }^{\circ}$, p. 41-42 se refiere al mismo cuadro que comenta Dědina, Mi tío y mis primas. Jiránek escribe su carta a Praga en octubre del mismo año, comentando la Exposición Mundial. Aunque opina que es floja incluso la colección inglesa y alemana - que describe como primeras (p. 40) - y otras, destaca lo siguiente: "una impresión tanto más triste producen dos antiguos países culturales, con una maravillosa cultura y pasado artístico, hoy desvaídos, sin jugo ni savia, en una decadencia absoluta: España e Italia ...» p. 41 agrega «... Pero otro pintor, pintor ciertamente no menos grande, - aunque no tengo demasiada alta opinión acerca de su valor artístico - Sorolla y Bastida expone toda una serie de trabajos, entre ellos el conocido lienzo "Cosiendo la vela», una de las pinturas más ardientes de plen-airismo que conozco, dos buenos paisajes, y un grande, asimismo magistralmente pintado cuadro Niños inválidos bañadose en el mar. Es un gusto genuinamentc español, pintar a tamaño natural toda una serie de pobres niños inválidos. Asimismo entiende que a pesar de todas las ventajas técnicas la impresión es sumamente desagradable. Ulpiano Checa agita su ímpetu en tamaños aun mayores sólo con menor resultado de color y arte. Conocidos «Carreras del circo romano» son el mejor ejemplo de su género. De manera similar, Moreno Carbonero ilustra en un lienzo enorme el duelo de don Quijote con los Molinos de viento - a tamaño natural! Pobre de Cervantes! Parece que cuando un artista en España ya no sabe absolutamente qué pintar más, - (y cómo es posible vacilar en un país que tiene dentro gitanas y bailarinas españolas?) - recurrirá al auxilio de don Quijote; aquí está toda una serie. - Pinturas al aire libre que exponen Pinazo Martinez y Carlos Vázquez son muy crudas en cuanto a color, pero me caen infinitamente más.simpáticas que el conocido R. Madrazo y los epígonos de Fortuny con asquerosas

$A E A$, LXXVI, 2003, 301, pp. 39 a 53 
También el escultor Josef Mařatka, uno de los pilares de la escultura moderna checa, como lo indica en sus apuntes, se relacionaba con relativa frecuencia con el pintor español Zuloaga en París mediante el maestro con quien estudió - nada menos- que el propio Auguste Rodin ${ }^{34}$. Parece que en el éxito de Zuloaga en el medio artístico de Praga pudo haber influido también la gran amistad del pintor español con el escultor francés, y por consiguente, su alumno y ayudante checo Mařatka, pues éste organizó el viaje y exposición triunfal de su maestro Rodin en Praga en 1902. Aprovechando su estancia en la capital checa, los artistas checos, encabezados por Maratka, llevaron y acompañaron a Rodin en una gira triunfal por el País, hasta Moravia. Asi, resulta lógico pensar que el viaje de Rodin a España en 1905 surgiera en su viaje a Praga. Asimismo la amistad de Zuloaga con el secretario de Rodin en aquella época, el poeta surgido en el ambiente praguense, Reiner Maria Rilke, pudo haber orientado e impulsado a Zuloaga a mandar sus obras a Praga; a su vez, Rilke quedó entusiasmado por España, especialmente Ronda ${ }^{35}$.

\section{La obra de Zuloaga en Praga}

Las citadas críticas favorables en revistas checas estaban preparando el terreno para que Zuloaga fuera invitado y ofreciera al público de Praga a finales del año 1904 y en 1905 un conjunto realmente rico integrado por: La bruja de Ansoa, El Monje penitente de Guadarrama, Retrato del matador Gallito y de su familia ${ }^{36}$, Retrato del alcalde de la ciudad de Torquemada, El marrullero, Gitana, A la espera, Viejas casas en Segovia, y el aguafuerte Españolas. Al año siguiente, en 1905, seguramente debido al impacto de la presencia anterior en Praga, Zuloaga vuelve a confirmar su fama con otro conjunto: Dos bebedores, Vendedor de miel, Gitana explicando los naipes, Danza en la terraza, Carmen, gitana danzante, A la orilla del mar en San Sebastián. El cuadro entonces reproducido en el catálogo, La danza en la terraza

pinturas de porcelana y cajas de bombones. Por otra parte, A. de Beruete (en el texto aparece Bernete, sic) expone varios paisajes grises, discretos y entre dibujantes refresca un excelente acuarelista, a quien las hadas le dieron un poco del viejo ímpetu y caballería española, Daniel Urrabieta Vierge. Así dos tres pintores, un dibujante, eso es un poco rico fácit del arte español...». A propósito del mayor rival de Zuloaga en la propia España, Sorolla, ésta es la primera mención del artista por un comentarista checo; la segunda sigue en la revista checo-alemana, en una Carta desde Berlín por lb. E.: Berliner Brief. Bohemia. 1904. n. ${ }^{\circ} 131,11-\mathrm{V}-1904$. p. 1, en la que se refiere a la pintura Einschleppen der Burke, llevando a los toros, finalmente, años más tarde, la misma revista Zlatá Praha publica en la primera plana la reproducción de la Vuelta de los pescadores, XXVIII, 1911, n. $^{\circ} 46$, p. 554, se cierra el ciclo de Zuloaga, de quien no se volverá a oir en revistas de arte en un artículo de José M. Junoy - Alexandre Planas, Mladé umění španělské (Joven arte español). Volné směry XVII, 1913, p. 211, 213, quienes condenan todo lo que no era la vanguardia del momento).

34 Josef Mařatka, Vzpomínky a Záznamy (Recuerdos y apuntes). Odeon Praha 1987, p. 98, 145, recuerda varias veces que conocía a Zuloaga gracias a que este pintor español fue amigo de August Rodin. La modelo predilecta de Maratka, Carmen Damendoza, una gitana española inspirada por la expresión artística de la bailarina Isadora Duncan, bailó en el cabaret de Zuloaga en la calle Lafontaine, de Paris. Está captada en una fotografía que regaló a Maratka con la dedicatoria: «A mon ami Carmen Damendoza». Véase asimismo Emanuel Siblík, Josef Mařatka. Praha 1935, p. 16: «El cuerpo danzante con un específicamente ibérico en la región lumbar, con una cabeza vuelta atrás a manera dionisiana así como con brazos moviéndose como reptiles, está captado aqui en una forma certeza de arcilla, plenamente vibrante, sin embargo, por el movimiento». Luego (p. 76 - 77) hace notar que Rodin le prefería a Carmen Damendoza «por su cuerpo logrado».

${ }_{35}$ Recientemente reconstruyó contactos de Rodin con España la exposición Rodin i la seva relació amb Espanya, Caixa de Pensions, Barcelona. diciembre 1996, en la cual fueron presentados ochenta trabajos (bronces, mármoles, dibujos, y fotografías) y además, treinta objetos de su colección privada, entre los que figuraba asimismo un cuadro de Zuloaga y una serie de cuadritos con temas españoles de Alexandre Falguiero. Arozamena, op. cit., nota 20, p. 142, reproduce el texto de una carta con la que Rilke agradece a Zuloaga el haberle invitado a su estudio.

${ }^{36}$ Una reproducción de este cuadro de principios del siglo xx, procendente de Munich, se conserva en las colecciones del palacio de Dačice, de Bohemia del Sur, n. ${ }^{\circ}$ inv. D 4975, nuevo 2015. Se trata de una reproducción de la Editorial Jugend de Munich (según indica el texto en la paspartout: Aus der Münchner Jugend. Vérlag der Münchner Jugend, $20,5 \mathrm{x}$ $19,5 \mathrm{~cm}$, lo cual demuestra la popularidad de que disfrutó la obra de Zuloaga en el ambiente de Bohemia.

AEA, LXXVI, 2003, 301, pp. 39 a 53 
$\left(\mathrm{n}^{\circ}\right.$ 961, fig. 13) puede relacionarse, sin duda, con los famosos cuadros Mis primas que surgieron con Segovia al fondo ${ }^{37}$.

Hace poco, el crítico Luboš Hlaváček captó la importancia de la exposición de Zuloaga para el medio ambiente praguense y especialmente el sentido de la confrontación que le daba a un pintor checo que por entonces aparecía con sus obras junto a Zuloaga, Ferdinand Engelmüller ${ }^{38}$ : en su exposición de cuarenta pasteles, el pintor checo tuvo como una «seria competencia - una colección de cuadros del español Ignacio Zuloaga, entonces un colorista célebre sobre temas folclóricos españoles, y un conjunto de pintores franceses, en el que Praga pudo ver, por primera vez con sus propios ojos a van Gogh, Gauguin, Renoir y Matisse. Para ... el artista checo fue una especie de duelo de exposición, en el que salió airoso pues al público de Praga le faltaba, hasta ese momento, una preparación estética imprescindible para entender las conquistas que traían los franceses».

En el mismo momento de la exposición la crítica y la prensa hizo todo lo posible para difundir la obra de Zuloaga y los ecos son muy numerosos, desde simples menciones verbales en resumenes de la exposición de la Unidad de Bellas Artes ${ }^{39}$ hasta reproducciones y análisis más pofundos, aunque fuera de una sola obra ${ }^{40}$ que siguen aún un año después de terminada la exposición. La popularidad de Zuloaga continuó durante mucho tiempo. Sirva como ejemplo un artículo anónimo probablemente de Karel B. Mádl, publicado en la revista Zlatá Praha en 1906, en el que dice: Praga tuvo la oportunidad de hacerse una buena noción de su obra; aquí cuatro reproducciones hacen revirirla en la memoria. Aqui habla la raza. En el pintor, en los modelos, en los cuadros. Esto ofrece una concordancia triple. El pintor eibarés no tiene nada que envidiarle en el temperamento, carácter, humor, vivacidad con lo que pinta, sea un viejo poeta del siglo quince don Miguel, sean señoras y señoritas, gitanas y vagabundas bien vestidas en la calle de la Afrodita. Todos viven, para nosostros quizá demasido, o con una gran preponderancia animada y parecen como siempre cargadas botellas de Leyden que descargan chispas siempre cuando se les toque. Por eso, todo está exagerado en ellos. El traje de vistosos colores, la mantilla excetante, las flores en el cabello llamativas, los labios rojos acabaron de ser pintados con la barra de carmín, las cejas negras con antimono, el cutis retocado con maquillaje y polvos, sólo los reflejos de sus dientes de rapaces y el relámpago de los ojos encantadores reconocen como bastante logrados por la naturaleza y suficiente para la conquista sin ayuda de nadie. Se entienede que este pitnor que tomó parte en la corridas, colecciona y estudia maestros antiguos y París aceptó la consagración técnico-artística, que este hombre, descendiente internamente de Velázquez y Goya, tuvo que causar agitación por dondequiera que apareciera. Su psicología no es nada amplia y sutil, pero casi siempre así recta, hasta impertinente, como lo exige la vida espiritual de sus modelos que pasean por la tarde en el mercado de amor sevillano, mirando desde el palco de la arena o sentadas al atardecer en un pasadizo como el pajarero en su puesto. Sus cuadros no cuentan ningún acontecimiento, sino que en ellos cuenta sólo lo que la gente piensa, cómo ven, cómo son, cada uno para

\footnotetext{
${ }^{37}$ Véase la monografía que rehabilitó a Zuloaga: Lafuente Ferrari, op. cit. nota 4, la cual registra de Praga tan sólo el hecho de que había presentado sus obras en esta ciudad (p. 93). La figura popular de Carmen apareció también reproducida en un cuadro del mismo nombre de Juan Cardona, Zlatá Praha, XXIV, 1907, n. ${ }^{\circ}$ 35, p. 417 (portada), muy cercano a Zuloaga por su estilo.

${ }^{38}$ Luboš Hlaváček, «Krajinář Ferdinand Engelmüller». Uměni XXXV, 1987, n. ${ }^{\circ}$ 5, p. 441.

39 R. O., Výstava krasoumné jednoty. Přehled, III, 1904/1905, c. 18, pp. 519-521 (se le menciona solamente); Dvě vánoční výstavy Krasoumné jednoty v Rudolfinu (Dos exposiciones navideñas de la Unidad de Bellas Artes en Rudolfinum). Čský svět I, 9-XII-1904, n. ${ }^{\circ 5}$, p. 166; M., V Rudolfinu (En el Rudolfinum). Zlatá Praha XXII, 1905, n. ${ }^{\circ} 10$, 23-XII.1904, p. 120 se refiere a los trabajos expuestos sin dar más detalles y un poco más tarde, otra vez en un artículo del mismo título V Rudolfinu, Zlatá Praha XXII, 1905, n. ${ }^{\circ} 33$, 2-I-1905, p. 396.

${ }^{40}$ F. X. Harlas publica las reproducciones de Alcalde de Torquemada y La familia del Matador Gallito en Kunstaustellungen III., Politik, 24-XII-1904, n. ${ }^{\circ} 355$, p. 1.
}

AEA, LXXVI, 2003, 301, pp. 39 a 53 
sí mismo, o algunos juntos. Su pincel no es de pelo fino, pero los colores que pone suenan plena y subidamente en combinaciones y armonías cuya extrañeza o incluso pícaro la deriva Zuloaga de lo llamativo de sus gitanas si no son brujas con el diablo en el cuerpo. Él mismo es ciertamente así, con el pincel en la mano y todo lo que antes de él los pintores no españoles vieron y pintaron en Iberia es, en comparación con él degradante. Aquí está el fuego, el ardor, grito del pueblo y de su naturaleza ${ }^{4 !}$.

Y por último, un párrafo del ya mencionado crítico Karel B. Mádl en el que comentó un cuadro, no expuesto en Praga, Mis primas en la serie de reproducciones publicadas en la revista Zlatá Praha aún el año $1907^{42}$. Vale la pena traducir todas sus palabras: «En la reproducción en blanco y negro, los cuadros de I. Zuloaga captan por su tipicismo de siempre, resuelto, enérgico, y feliz de sus apariencias raciales. En el original, como los praguenses ya se habian convencido por sus propios ojos, asciende y aumenta su vivacidad con la profundidad subida y su composición y contrastes sureñamente blandos. Después de Goya, Zuloaga fue el primero en la pintura española en tener coraje frente a la realidad. Además, siempre se equipara a sus modelos en temperamento pletórico que logra excitar incluso a un observador indolente. Nada embellece, no generaliza; por otra parte, contiene una vida de por diez. Estas tres «primas» viven delante de nosotros en el cuadro, morenas, de cejas negras, con ojos diabólicos en caras tan pintaditas, excitantes en cada movimiento, cocotas desde la punta del pie hasta el blanco reflejo de dientes, están caminando a vuestro lado como si trajeran en sí mismas el contenido y lo seductor de su propia raza».

Entonces, Zuloaga estaba en la cumbre del reconocimiento internacional y, esto, naturalmente, repercutía asimismo, en la apreciación de la crítica de arte checa prácticamente hasta que el inicio de la primera guerra mundial cortara el contacto con París y España ${ }^{43}$.

Los dos conjuntos expuestos en Praga en 1904 y 1905 fueron enumerados y comentados muy poco tiempo después, en 1908, aunque con reservas y en tono crítico, en el diccionario Ottúv slovník naucny ${ }^{44}$ que sigue siendo una importantísima fuente de informaciones hasta hoy: «expuso dos grandes grupos de retratos, pinturas grandes al óleo que en su incisa característica y el dibujo preciso sufren, en conjunto, por unos tonos oscuros hasta sucios, sin luz y luego, por aplanamiento. Por esta razón impresionaban más los aguafuertes titulados «Españolas»y «Paseo después de la corrida de toros». Evidentemente, al crítico no le gusta-

${ }^{4 I}$ Zlatá Praha XXIII, 1906, n. ${ }^{\circ} 15,19-$ I-1906, p. 179 (texto) reproduciendo cuatro obras de las expuestas hace un año: Ulice lásky (Calle de amor), p. 169; Miguel, Gitana y V loži na Plaza de Toros (En el palco de la Plaza de Toros), todas en la p. 172.

${ }^{42}$ K. B. Mádl, Zlatá Praha XXIV, 1907, n. ${ }^{\circ} 26.29$.III. 1907, p. 308, texto p. 316 (Pohribný, 1269). Firmado con un trifolio comenta aun mucho más tarde a Zuloaga en su artículo Výroční výstava v Rudolfinu (Exposición anual en Rudolfinum). Národní Listy, 12. 5. 1912, en una crítica global de dicha exposición (p. 593. n. ${ }^{\circ} 1631$ Pohribný), acompañado de la reproducción del cuadro Mis primas.

${ }^{43}$ Incluso cuando el objetivo del comentario es distinto, Zuloaga aparece como punto de comparación; véase por ejemplo M. (Mádl?), Výstava Émia Bernarda, Zlatá Praha XXVI 1909, n. ${ }^{\circ} 21$, p. 251; del Salón de París del mismo año aparece el cuadro La señorita de Bréval en el papel de Carmen, Zlatá Praha XXVI, 1909. n. ${ }^{\circ}$ 3. p. 32; A Zuloaga se le utiliza como punto de referencia en caso de tales pintores como es William Laparra; véase E. Tito, Milostné historky - Wiliam Laparra, Cestou (Historietas amorosas - En el camino). Zlatá Praha XXVI. 1909, n. ${ }^{\circ}$ 52, p. 621. Al año siguiente, aparecen reproducciones de Castilla la Vieja en Zlatá Praha XXVII, 1910. n. ${ }^{\circ} 35,20-\mathrm{V}-1910$. p. 409; Española durante la corrida de toros, Zlatá Praha XXVII, 1910, n. ${ }^{\circ}$ 39, 17-IV-1910, p. 464; Dama con abanico, Zlatá Praha XXVII 1910, n. ${ }^{\circ} 43$, 15-111-1910, p. 513. El mismo año vuelve a prestarle atención A. Macek. Besedy lidu XVIII. 1910. n. ${ }^{\circ} 18$, p. 287, reproduciendo Don Miguel y La calle de Amor, p. 284, igual que el año siguiente, A. Macek, Besedy lidu XIX, 1911, n. ${ }^{\circ} 6$. p. 88. repr. En el palco de la Plaza de toros, p. 95 y Gitana, p. 89; A. Macek, Besedy lidu XXII 1910, n. ${ }^{\circ} 21$, p. 325, ilustrándolo con La víctima de la fiesta, p. 334. Continúa recordándosele en un comentario a la exposición de la Unidad de Bellas Artcs aún en 1912 - M., 72. výroční výstava Krasoumné jednoty (72a exposición anual de la Unidad de Bellas Artes. Zlatá Praha XXIX, 1912, n. ${ }^{\circ}$ 36, 24-V-1912, p. 433 y cierra el ciclo prebélico Zlatá Praha XXX, I 913, n. ${ }^{\circ} 3$, 27-IX-1913. p. 28, volviéndolo a reproducir La víctima de la fiesta.

44 Autor: F. M., Ottúv slovnk naucny, 27. Praha 1908. p. 708. La característica se refería sobre todo al conjutno presentado en la Exposición especial. El segundo aguafuerte Paseo después de una corrida no se encuentra en el catálogo.

AEA, LXXVI, 2003, 301, pp. 39 a 53 
ban los elementos fundamentales de carácter modernista y simbolista que por aquel momento comenzaban a pasar de moda y que sería posible analizar a base de las tendencias de la época.

Más tarde, también el maestro y clásico de la historia del arte checa Antonín Matějček incluyó a Zuloaga en su breve historia del arte enlazándole con la línea del arte moderno desde Velázquez y Goya hasta Manet: «Con el negro hispanismo manetiano enlazó el vasco Ignacio Zuloaga, pintor de la vida pintoresca castellana. Apoyándose en Velázquez y Goya, Zuloaga se esforzaba por una síntesis monumental de la realidad y la visión romántica con una mano virtuosa» ${ }^{45}$.

Aunque Zuloaga se convirtió en el blanco de los ataques de la generación entrante en la escena bajo la bandera del arte moderno, desde su propia tierra natal, España ${ }^{46}$, su obra seguía teniendo en Praga un buen eco incluso en el ámbito fuera del campo de las artes plásticas ${ }^{47}$.

No hay que olvidar que junto con Zuloaga representaron el año 1905 a España también otros pintores españoles, entre ellos Iturrino, Navarro y García Rodríguez, José Gallegos y Arnosa, José Navarro Lloréns y Manuel García Rodríguez. Sin embargo, como acabamos de ver, la mayor atención la despertaba, como trata de demostrar este artículo, precisamente el representante de la generación del 98, Zuloaga.

\section{El impacto de Zuloaga sobre Karel Myslbek}

No puede pasarse por alto el heclio de que la obra de Zuloaga marcó una profunda y decisiva influencia en el pintor Karel Myslbek, cosa que entendieron inmediatamente todos los críticos, en primer lugar Karel B. Mádl, aunque él inismo protestó contra una generalización excesiva en este sentido: «Debido a que hoy incluso en Praga saben del arte de Ignacio Zuloaga, y pues le llamaron la atención, figuras únicas en el cuadro o sus grupos no académicos, sus siluetas esporádicas y los momentos sin argumento, así como sus profundos, a la oscuridad sumergentes colores, no habría de extrañarse, si el joven Myslbek les trajera inmediatemente a la memoria dicho español» ${ }^{48}$. Lo explica tomando corno argumentos lo que parece convenien-

\footnotetext{
45 Antonín Matějček, Dèjepis uměni, 6. (Historia del arte, 6). Praha 1936, p. 164.

${ }_{46}$ Junoy-Planas, op. cit. nota 33. p. 209-210: «El pintor Zuloaga tuvo éxitos en París aun antes de que la fuerza de la provocación de su arte fuera reconocida en Madrid; su secreto está en una visión del alma española, espléndida y trágica... qué movimiento extraño y excitante aprisiona este arte español, cuyo máximo exponente es Zuloaga, movimiento deformante y corrumpiendo lo más plástico y que daba la forma al mundo que no existe? Por eso la España de Zuloaga es artificial, es una creación de fiebre. Contra Zuloaga se escribieron muchas cosas, pero no ha habido una mano lo suficientemente fuerte para abatir este artista de tremenda técnica y extraordinaria falta de sinceridad...». (traducción mía al español - P. S.).

${ }^{47}$ Según la amable comunicación del dr. Fr. Dvořák fue un gran admirador de su obra el escenógrafo del Teatro Nacional de Praga, J. M. Gottlieb, pintor y alumno del polaco Matiegka.

${ }^{48}$ Véase Karel B. Madl, «Karel Mysbek» ( 1908) in: Karel B Madl. Výbor z kritických projevů a drobných spisu (Selección de discursos críticos y escritos menores). Praha 1959, p. 318, y «Z vystavy Mánesa» (De la exposición de la agrupación «Mánes»), ibid., p. 328. También escribió sobre dicha exposición Karel Čapek, «Z výstavy obrazů prof. Karla Myslbeka» (Acerca de la exposición de cuadros del prof. Karel Myslbek). Snaha, 26.5.1908, in: O uméní a kultuř I. Karel Čapek, Spisy XVII Praha 1984, p. 29. «Lo más interesante de esta exposición de modestas proporciones es, sin duda, el claro e instructivo caso que nos presenta la conquista del sr. Mylsbek de un pintor a un futuro escultor, la influencia de los viejos maestros españoles (Velázquez) y Zuloaga quien hizo anclar.su admirable arte en esa tierra firme. Bajo el único y ciertamente buen intento de solucionar problemas del nuevo estilo (estudio de una joven a la luz natural), el sr. Myslbek dejó aparte las conquistas de la paleta moderna y volvió todo su esfuerzo a grandes lienzos con figuras de traje a tamaño supranatural pintados con la mayor sobriedad de colores y una manera fuerte simple. La influencia de los maestros españoles ya está clara y después de un viaje a España, donde el sr. Myslbek tuvo la posibilidad de ver a sus queridos cara a cara, su esfuerzo todavía más fuerte lleva el sello del ver oscuro, lúgubre y bizarro de esos maestros. De la misma manera podría pintar los campesinos y los obreros, si en aquellos españoles no hubiera adqurido aquel gusto penetrante por lo grotesco que excluye toda emoción social. El estilo de lo bizarrro consiste en los contornos, en la silueta, en un dibujo expresivo y plástico y en un colorido simple que sólo sirve para que expresara la materia cuando ya no hay necesidad de ocuparse de problemas de la luz y del aire. De ahí ya no hay mucha distancia a la escultura».
}

AEA, LXXVI, 2003, 301, pp. 39 a 53 
te recordar precisamente aquí: (Myslbek) «Tiene todos esos síntomas exteriores. Si Vds. miran su Torrida (sic, debe decir Corrida), mitad a la sombra, mitad al sol palpitante, si Vds. encuentran en el catálogo nombres como El Escorial y Sevilla, saldrán convencidos hasta el final de sus días de que el arte de Karel Myslbek había saltado de España a Bohemia, que es un exotismo, muchas veces materia y casi por todas partes incluso forma. Así no se equivocarán mucho. Dichas relaciones no pueden negarse ni callarse. Una excursión a Italia, una estancia en París, andanzas por Flandes no son hoy nada de particular en nuestros artistas. Sin embargo, una jira por España, si alguien es dueño del lienzo, de pinceles y de una caja de colores entre su equipaje, es algo nuevo, sí, desacostumbrado. Podemos suponer, por cierto, que al joven artista le habrá atraído allá algo interior, ya que no hay ni pista de unas vistas turísticas de la Alhambra de Granada. Pasó al lado de ellos y no fue (a España) por ellos. Y extraño o sintomático es asimismo que sus un poco vacilantes acuarelas de los mercados y aguas españolas no tienen el encanto, claridad ni romanticismo de exportacion de un don Juan, ni una aventura sensual excitante de la Carmen. Son pesados y lúgubres.

Esta es también la cara típica de todo el arte de Karel Myslbek Tiene una sangre pesada y espesa, Zuloaga no pudo haberle servido en esto de modelo, el Zuloaga cálido, fervoroso y temperamental como torero, con el cual comparte también una visión común penetrante intrépida, y domina el pincel como aquel muletas. Da con el blanco de un solo tiro ... El arte de Zuloaga es sureño, y por consiguiente, luciente, colorista... (subrayado por P. S ${ }^{2}$.) ${ }^{49}$. Dejaremos para otra oportunidad el análisis de la obra de Myslbek y nos contentaremos con la vista crítica de la época para subrayar así el prestigio que Zuloaga disfrutaba en aquél momento en el ambiente checo.

\section{Zuloaga coleccionista de E1 Greco y Vincenc Kramár}

Sin embargo, el papel de Zuolaga como pintor atrayente incluso para la práctica pictórica no se agota ni termina ahí. Es que fue también un coleccionista importante, que supo captar en sus gustos el espíritu de la época y plasmar una colección que ayudó a descubrir para el siglo $\mathrm{xx}$ a un pintor español que se había convertido en revelación después de siglos de olvido: El Greco. «Zuloaga fue, de hecho, el descubridor de El Greco en el siglo XX» y sus amigos le apodaban «Le Greco» ${ }^{50}$. Lo que se buscaba en la obra de El Greco, fue ante todo la «infinita libertad, como se entendían ahora sus «extravagancias» de antaño, lo que podía servir de apoyo a (estos) artistas para afirmar sus propias posiciones» ${ }^{51}$.

El autor vuelve otra vez a la influencia de Zuloaga sobre Myslbek en la reseña de la $47^{a}$ exposición de la agrupación SVUM (Mánes): Lumír, 5.5.1916. idem., p. 423: «K. Myslbek, espiritu serio e infeliz que se esforzaba fatigosa y duramente por el gran realismo epañol, tal como fue interpretado sobre todo por Zuloaga y que amasaba sus grandes figuras como inamovibles, pesadas esculturas, inundadas por una media luz turbia, intransparente...».

Algunas condenas a posteriori de la obra de Zuloaga en nuestro país como lo observamos por ejemplo en Zdeněk Pilar̆, Karel Myslbek Praha 1954, p. 29, parecen ser más bien páginas de humor negro que de crítica de arte, pues dice: «De los artistas contemporáneos se atribuía una gran influencia sobre Karel Myslbek al español Zuloaga. Fue un pintor de moda, en su época bastante famoso. Como temas de sus cuadros escogía ante todo escenas de la vida de los españoles, sobre todo de varias fiestas y ferias para poder captar a jovenes bellas en trajes populares de fiesta bajo el ardiente sol del sur. Dichos temas le servían para tocar el rico registro de violentos colores contrastantes, con los que modeló, en tonos puros, sus figuras, concebidas, en su mayoría, a tamaño natural. La impresión de sus cuadros es que son demasido variopintos, demasiado llamativos, sobre todo allí donde pasa a una estilización decorativa. Zuloaga es un pintor superficial que quiere maravillar al observdor, consternar con su artificio de fuego colorístico, no piensa en el contenido, se limita a ser difrutado por la flor y nata del público burgués.» (subrayado por P. S.).

49 Mádl, op. fit. nota 48. p. 319.

${ }^{50}$ Lafuente, op. cit. nota 5, p. 74, 7.

51 María de los Santos García Felguera. Viajeros, eruditos y artistas. Los europeos ante la pintura española del Siglo de Oro. Madrid 1991, p. 146. Sobre su influencia a principios del siglo véase también Jordi González Llacer, El Greco y

AEA, LXXVI, 2003, 301, pp. 39 a 53 
Recordemos simplemente un solo hecho: cuando Vincenc Kramár̆, teórico y coleccionista del cubismo, especialmente de obras tempranas de Picasso, quiso ver un poco más tarde, en 1911 la famosa coleción de los Grecos que Zuloaga reunió, se dirigió, como él mismo trae a la memoria ${ }^{52}$, al propio Pablo Picasso, de quien comenzaba a coleccionar sus obras, para que le recomendara a Zuloaga, lo que efectivamente ocurrió, y por escrito.

Como lo muestran más tarde las fotografías tomadas en el taller español de Zuloaga (cuando este volvió de París), el pintor tenía, entre otras cosas, el cuadro Apertura del quinto sello (hoy en el Museo Metropolitano de New York), que se había convertido en obra emblemática de El Greco, analizada y parafraseada por pintores checos, siguiendo al propio Picasso a quien le sirvió de modelo en su obra clave, las Señoritas de Aviñón ${ }^{53}$. Dicho contacto entre Kramár, Picasso y Zuloaga fue mediado, sin embargo, por Henry Kahnweiler, el principal suministrador de los cuadros de Picasso a la colección de Kramář y de informaciones acerca del joven pintor español afincado en París, requeridas constantemente por Kramář. En aquella oportunidad, el día 29 de mayo de 1911, Kahnweiler escribió a Kramář: «Zuloaga está en París. Adjunto le mando una carta de recomendación escrita por Picasso. Picasso le aconseja que vaya con dicha carta a ver a Zuloaga mañana hacia las 12 horas, pues a esta hora se le puede ver mejor. Luego podrá ver la colección inmediatamente, o eventualmente, acordará con Zuloaga la hora de la larde, a la que podría volver a verle. Con cordiales saludos su afectuoso Kahnweiler ${ }^{54}$.

$\mathrm{Si}$ agregamos el texto del propio Picasso, vemos que le escribe a Zuloaga en un tono a la vez muy cordial, respetuoso hasta reverencial, aunque no exento, en su brevedad, de cierta insistencia, hasta presión: «Señor/ Don lgnacio Zuloaga/ ${ }^{54}$ rue Coulsincourt/ Montmartre/ Amigo Zuloaga/ Quiere/V. enseñarle sus Grecos al/ Señor Kramar de Viena que le presento/ que ha hecho casi el viajel por verlos. Si hoy no/ puede ya le dirá V. cuando/ puede verlos./ Anoche sentí no verlo/ a V. en el «Lapin Agile» mel dijeron despues que había/ V. estado a comer y yo estabal también./ Gracias Maestro y/ mande a su amigo/ Picasso/ 11 Bd. de Clichy/ 27 mayo 1911» ${ }^{55}$. Así, el gran promotor del Greco y del cubismo pudo conocer gracias a Picasso no sólo los Grecos, sino también a Zuloaga, aunque, ciertamente, no hubo entendimiento acerca de su propia pintura que Kramár, portavoz de la nueva tendencia y generación, debía, si no rechazar, por lo menos no aceptar.

Luego, después de la primera guerra mundial volvemos a ver pocas veces el nombre de $\mathrm{Zu}$ loaga en la prensa especializada checa, menos algunas excepciones ${ }^{56}$ y una sorprendente necrológica tras la muerte del artista en $1945^{57}$.

\footnotetext{
su influencia en los albores de la modernidad, Galería Antiqvaria XV, 1997, n. ${ }^{\circ}$ 148, p. 42-47, reseña de la exposición en el Museu Nacional D'Art de Catalunya. Sin embargo, la influencia de El Greco fue mucho más amplia de lo que se reconoce, según advierte Zdeněk Rotrekl, Barokní fenomén v současnosti. Praha 1995, p. 126 alcanzando pintores como Jan Zrzavý y al teórico Karel Teige.

52 Vincenc Kramáŕ, Domenico Theotocópuli El Greco. Uméní, 1990, c. 6, p. 511, ed. K. Srp. El Greco fue objeto de análisis de varios artistas checos, en primer lugar J. Borovicka. El Greco (Dojmy ze Španělska). (Impresiones de España). Umélecký mésičník, I, 1911-12, p. 67-73 y luego, el texto que volvió a publicarse varias veces, de Emil Filla, El Greco. Umèlecký měsičník, I, 1911-12; últimamente Emil Filla. Práce oka. Praha 1982, p. 12-25.

53 Rolf Laessoe, A source in El Greco for Picasso's Les Demoiselles d'Avignon. Gazette des Beaux Arts, Oct. 1987,1425 Liv. 129e A., p. 131-135.

54 Vojtěch Lahoda, Český kubismus (El cubismo checo), Praha 1996. p. 99. El original de la carta está en el archivo de la Galeria Nacional de Praga.

55 Véase la reproducción facsímil del texto en Eva Petrová. Picasso v Československzi (Picasso en Checoslovaquia). Praha 1981, p. 78-79.

${ }^{56}$ Por influencia alemana — podemos creer - se presta atención, en plena Segunda Guerra Mundial, a la exposición del arte español en Berlín en 1942, de la cual la revista Světozor, 42. 1942. n. ${ }^{\circ}$ 6. p. 72 trae una reproducción del retrato del pintor Arango.

57 Como tal podemos considerar las últimas menciones de Zuloaga: la primera la encontramos en una referencia a las adquisiciones del Louvre, publicado por -om- (Otakar Mrkvička?), Rovnost, 1945, n. ${ }^{\circ}$ 71, p. 3, mencionando tres lienzos, y Svobodné noviny, I, $1945, \mathrm{n} .{ }^{\circ} 142$. 8.X1.1945, p. 3. Una necrológica propiamente dicha aparece en la revista Uméní XVIII, 1946 , n. ${ }^{\circ} 5-6$, p. $234-235$.
}

$A E A$, LXXVI, 2003, 301, pp. 39 a 53 
Así, a manera de colofón puede resumirse que Zuloaga dejó una profunda huella en el país checo, pues contribuyó a enriquecer mucho su panorama plástico, pues primero fue modelo para uno de los pintores checos más importantes del primer decenio del s. Xx, Karel Myslbek; segundo, fue objeto de atención de muchos otros que al mismo tiempo cultivaban la crítica de arte (Dědina, Jiránek, Mádl), cuyas palabras siguen válidas hasta hoy, y, por último, ayudó a conocer la obra de El Greco, impulsando así a formar el gusto de la generación venidera, que se identificaba con la vanguardia (Kramář y el grupo de los pintores Osma).

9. Apéndice documental: Obras de Ignacio Zuloaga (y Zabaleta) en las exposiciones de Praga

Nota: Las cifras a la derecha expresan el precio de venta, según el catálogo de la época.

1. ${ }^{\text {er }}$ conjunto: 66. ${ }^{a}$ Exposición especial de la Unidad de Bellas Artes para Bohemia diciembre 1904-enero 1905:

I. Ferd. Engelmuller, II. Salon International de la Gravure en Couleurs, III. Ignacio Zuloaga

201. La bruja de Ansoa

202. El Monje penitente de Guadarrama

203. Retrato del matador Gallito y de su familia

30.000

204. Retrato del alcalde de la ciudad de Torquemada $\quad 15.000$

205. El marrullero (Hipócrita?) $\quad 8.000$

206. Gitana $\quad 8.000$

207. A la espera $\quad 5.000$

208. Viejas casas en Segovia $\quad 4.000$

209. Españolas aguafuerte (Rad/ierung) $\quad 50$

2. ${ }^{\circ}$ conjunto: Lista de la $66 .^{a}$ Exposición anual de la Unidad de Bellas Artes para Bohemia en Praga 1905:

957. Dos bebedores / Die beiden trinker. Ól.

958. Vendedor de miel / Der Honigverkaufer. Ól. No hay precio.

959. Gitana echando las cartas / Karten legende Zigeunerin. Ól.

961. Danza en la terraza / Tanz auf der Terrasse, Ól., repr.

962. Carmen, gitana danzante / Carmen, tanzende Zigeunerin. Ól.

963. A la orilla del mar en San Sebastián / Meerstrand in San Sebastian.ól. 